\title{
Animalidade, Moral e Subjetivação: pelo reconhecimento da alteridade para além do outro-humano
}

Animality, Moral, and Subjectification: for the otherness recognition beyond the other-human

Rodrigo Avila Colla*

Pontifícia Universidade Católica do Rio Grande do Sul

Resumo $\mathrm{O}$ ensaio discute a animalidade enquanto qualidade intrínseca do humano. Atenta para seu potencial como esfera formativa sensível e a defende como via para a criação de modos de subjetivação alternativos. Busca desvelar certo condicionamento natural inerente às normas morais. Nietzsche (2005) e Schiller (2002) ajudam a situar a gênese da moral e as motivações que levam o humano à socialização. Guattari (1992; 2003) contribui para a fundamentação de um paradigma alternativo de subjetivação no que tange ao tópico da animalidade. Esse paradigma visa a dar margem a vias de subjetivação heterogêneas e abertas à alteridade absoluta, esfera de infinitas alternativas subjetivantes. Por fim, sugere-se que a animalidade seja repensada como elemento de potenciação da sensibilidade na Educação.

PALAVRAS-CHAVE: Animalidade, Educação Moral, Subjetivação.

Abstract This paper discusses the animality while intrinsic quality of the human. Attempts to their potential as sensitive formative sphere and defends it as a way to create alternative modes of subjectification. Seeks to unveil some natural conditioning inherent to the moral standards. Nietzsche (2005) and Schiller (2002) help to situate the genesis of morality and the human motivations that lead to socialization. Guattari (1992, 2003) contributes to the foundation of an alternative paradigm of subjectification regarding the topic animality. This paradigm seeks to give rise to subjectification ways heterogeneous and open to the absolute otherness, sphere of infinites subjectivizing alternatives. Finally, suggests that the animality be reconsidered as element of exponentiation of the sensitivity in Education.

KEYWORDS: Animality, Moral Education, Subjectification. 


\section{Apresentação}

É devido a sua vontade de transcendência que a espécie humana recai na ética. O livre vivenciar puramente instintivo do animal-humano dá lugar, com isso, a um animal de ciência e de moral, construtor e autoconstituidor, que se acultura e recodifica as leis naturais segundo parâmetros inter-humanos. Assim,

Se a razão suprime, portanto, o Estado natural para substituí-lo pelo seu, como tem necessariamente de fazer, ela confronta o homem físico e real com o problemático e ético, confronta a existência da sociedade com o Ideal apenas possível (ainda que moralmente necessário) de sociedade. (SCHILLER, 2002, p. 24)

Não obstante, a própria sociedade não é dada naturalmente. Não é uma insurgência automática de certo estado de coisas orgânico. A educação é o processo pelo qual, ao educar os indivíduos moralmente - para os costumes da sociedade aqui entendidos de maneira ampla - se os educa, evidentemente, ao mesmo tempo, para serem humanos e para viverem em sociedade. É, em outras palavras, o processo em que o humano desde muito cedo aprende a ser humano para servir à sociedade.

A sociedade, por sua vez, é erigida de acordo com certas restrições naturais e sua formação dialoga com as condições do meio em transformação, mas sua forja advém da vontade de transcender essas restrições. A transcendência do mero estado de animalidade vem sendo, ao longo dos tempos, a grande aventura do animal-humano. A Educação, desse modo, visa a humanizar o animal do gênero homo para torná-lo um animal social e para lhe propiciar meios de transcendência desse estado. Como afirmava Émile Durkheim (1978), a sociedade quer educar os seus membros para certa unidade no pensar e no agir que the possa assegurar o caráter convival desejado e certa harmonia relativa.

Em sociedade, os homo sapiens sapiens são educados para viverem em autotransição e, humanizados e em vias de humanização progressiva, serem moventes da sociedade, também em constante transformação. A humanização desde sempre foi uma ferramenta em prol da socialização. Educa-se o animal do gênero Homo para ser humano para que a sociabilidade seja possível. O problema parece residir no fato do processo educativo-humanizador ao longo dos tempos ter demonizado tudo que há de animal no Homo. Hoje, por exemplo, se fala em educar integralmente o ser humano. Uma educação que desenvolva o ser humano como um todo parece requerer, no entanto, o traquejo e desenvolvimento da animalidade inerente ao humano.

É, por outro lado, a simples possibilidade do Ideal sempre aperfeiçoável que move o desejo humano de agir melhor, bem como seu afã de estar acima do estado de animalidade. Moveu-o da natureza à cultura, da animalidade a sociabilidade, e continua a movê-lo num processo de humanização a cada dia mais tecnicista. De qualquer modo, o humano, para se constituir para além do natural, idealiza (e busca pôr em prática) condições de convivência com vistas a se elevar em sociabilidade. Os humanos bem humanizados e socializados, por conseguinte, querem se resguardar da animalidade inerente de seus consentâneos menos humanizados e menos conscientes 
da equalização ética necessária à sociedade. Não por acaso, antigamente, a Educação era privilégio de poucos (da nobreza) e gradativamente foi se percebendo a necessidade de educar a população em sua quase totalidade. Educar é, pois, tornar a socialização e o convívio possíveis e tolher impulsos nocivos a esses fins. A liberdade humana (aqui entendida como transcendência em relação à animalidade) é, paradoxalmente, sempre relativa e só pode existir entre humanos, portanto, em sociedade. $\mathrm{O}$ humano se torna humano pela socialização. Para tanto, enquanto mecanismo socializador e humanizador, a Educação, por assim dizer, interdita uma série de impulsos animais que tendem a vir à tona espontaneamente. Jaz aí a ressalva imprescindível: há humanos desejosos de libertar o animal-humano de sua animalidade instintiva, mas, para tanto, atribuem aos atos orientados pela animalidade humana estatuto de antiéticos, incorretos, impudicos, contrários à decência e à humanidade. Os desvios da boa-humanidade são tornados incomutáveis crimes de ser-menos ou, para dizer o mínimo, imputam o caráter de hábitos desvirtuantes legalmente legitimados. A própria palavra "desumano" é hoje sinônimo de "cruel", quando na verdade indica apenas "falta de humanidade". Seria a humanidade essa qualidade incontestavelmente boa e de maneira alguma má? Ora, pela lógica maniqueísta que aí jaz é possível deduzir que, se "humanidade" é o bem, "animalidade", pelo menos no que se refere à formação humana, é o mal.

O "bom", etimologicamente falando, é aquele que, por gratidão ou vingança, tem capacidade de retribuir, o "mau" é o impotente (NIETZSCHE, 2005). Nesse sentido, cabe seguir essa problematização com Nietzsche: "Não atribuímos valor especial à posse de uma determinada virtude, até que percebemos a sua ausência total em nosso adversário." (2005, p.182). É a intencionalidade inerente à razão que se alia aos sentidos e faz vir à tona os juízos que, no âmago da racionalidade, vão servir como marcas e fulcros de hábitos distintivos. Conclui Nietzsche: "Nossa moralidade atual cresceu no solo das tribos e castas dominantes." (2005, p. 49), não sem antes reconhecer que sem os erros das suposições morais os homens teriam permanecido animais e que, somente por meio delas, os dominantes se tomam "por algo mais elevado" e nutrem verdadeiro ódio pelos "estados que ficaram mais próximos da animalidade" (2005, p. 47).

Não é surpreendente, assim, que indícios de animalidade, mesmo quando proporcionam vazão a certa originalidade e traquejo do estado sensível do animal-humano, sejam delegados ao estatuto de agir inferior. Não obstante, como bem lembra Friedrich Schiller

A natureza não trata melhor o homem que suas demais obras: age em seu lugar onde ele ainda não pode agir por si mesmo como inteligência livre. O que o faz homem, porém, é justamente não se bastar com o que a natureza fez, mas ser capaz de refazer regressivamente com a razão os passos que ela antecipou nele, de transformar a obra da privação em obra de sua livre escolha e de elevar a necessidade física à necessidade moral. (SCHILLER, 2002, p. 23)

Foi, portanto, o desejo de libertar-se da animalidade humana que levou o humano a aprisionar animais, e animais congêneres, e criar instituições para dar conta desses modos de confinamento e controle. Uma delas, por exemplo, é a escola. Foi, paradoxalmente, a ânsia por liberdade que fez do humano um animal moralista/ 
moralizante e aprisionador/educador do outro. É claro, para viver em humanidade, é preciso humanizar-se, não há dúvida. Os meios pelos quais foram feitas assepsias de animalidades é que poderiam ser criticados. $\mathrm{O}$ estado de repulsa à origem animal inegável é que, além de inoportuna, torna-se ingênua frente à própria condição natural inescapável. A busca pelo completo ofuscamento do Estado natural, entretanto, parece implicar certo embotamento dos sentidos físicos e, por consequência, uma relativa redução dos sentidos aos sentidos racionalizáveis. Ora, em se tratando de objetivar a formação integral do humano, não seria esse caminho subjetivante um tanto homogeneizador e enclausurante, uma vez que lhe faz negar a única qualidade que é sua por natureza, a animalidade?

Neste breve ensaio, como talvez já tenha ficado patente, quero, em suma, argumentar a favor da reflexão da animalidade na formação humana como condição sine qua non da humanidade que se constitui moral pelo viés da sensibilidade. Isso se dá por três motivos. (I) Trata-se de uma condição física, a qual jamais se poderá expulsar ou confinar totalmente do humano, e que, quando muito, pode ser amansada, mas, todavia, deve-se considerar que nesse tipo de processo, para ganhar-se algo (humanização) perde-se outra coisa (animalidade). Todavia, essa animalidade reside na própria gênese da comunidade humana no que tange aos costumes, à criatividade e à moralidade. (II) Assim, a própria moral se erige com a influência de contextos ambientais, potências e necessidades animais inerentes a esses contextos. (III) Por fim, pretendo demonstrar alguns modos de contenção da animalidade que se perpetuam por meio de certa racionalidade e defender as qualidades animais, enquanto condições a priori inerentes aos animais-humanos, como vias de resgate da sensibilidade que contribuam na condução a uma moral sensível à vida e ao outro e deixem escoar outras possibilidades de subjetivação que, por seu turno, guiem a novas alternativas de condutas e morais humano-animais.

Certa equalização entre animalidade e humanidade, por certo, é recomendável para a construção de sujeitos éticos e sensíveis ao outro, mas recair em excessos de humanização, segundo minha hipótese, leva a um estado de apatia que, ao insensibilizar o sujeito em relação ao seu estado original, insensibiliza-o quiçá em relação à única condição a priori que ele pode encontrar nos seus semelhantes.

Em tempos em que a tecnologização e a tecnificação dos modos de humanização se tornaram realidade - e certos romances e filmes de ficção científica já nos soam muito mais proféticos do que fictícios - discutir a animalidade inerente a homens e mulheres que, em seus processos de subjetivação se aproximam de sujeitosciborgues lançando-se em processos de cibernetização, torna-se não só pertinente, mas imprescindível. A sugestão de Edgar Morin (2006) de que para que sejamos verdadeiramente humanos devemos estar conscientes de nossa animalidade se torna, assim, a cada dia mais atual.

\section{A Inarredável Animalidade do Animal-moral}

Poder-se-ia, em última instância, lançar a provocação: mas o que há de tão superior na espécie humana, que tal qual as mais naturalizadas, de algum modo conti- 
nua a digladiar-se por fêmeas/machos e por territórios e reside presa a seu Estado de necessidades e defende-se ou corre ou esconde-se quando se sente ameaçada e parece, em última análise, ao invés de libertar-se, apenas ampliar ainda mais seu rol de necessidades à medida que se humaniza?

São, por certo, perguntas que carregam certo teor retórico, não obstante, em princípio, e porque não dizer, também na prática, humanos, somos também animais inextricavelmente atados ao Estado natural. Ademais, nos deparamos o tempo todo com essas lutas animais que as instituições não conseguem apagar. Nesse sentido, não há como fugir da animalidade, não há como obliterar completamente o instinto nem há como cobiçar a completa fuga do animal imanente e todo contingente de pulsões que traz consigo. Talvez seja o momento de utilizar essa potência animal em favor de uma educação criativa e redimensionadora da moral no tocante à insurreição de outros-eus-possíveis.

A moralização dos costumes e o regramento dos atos é, em certa medida, o que permite que se viva em comunidade, mas a própria moral traz consigo o problema da negação do desvirtuante. Aliás, sequer viver em comunidade é uma primazia da espécie humana. A existência da norma, enquanto condição de pertença, também não se dá simplesmente por lucubrações do intelecto humano privilegiados. "Em sua criação física, a natureza aponta-nos o caminho a ser percorrido na criação moral”, diz Schiller, e complementa: "Somente depois de apaziguar a luta das forças elementares nos organismos inferiores é que ela se ergue até a nobre formação do homem físico." (SCHILLER, 2002, p. 43). Certo Estado natural, portanto, subjaz qualquer regramento arbitrário e intelectualmente estabelecido. A própria significação de algo em si tenderá a estar relativamente ligada à instância pragmática de algo, não raro tendo de considerar também o fenômeno que o faz vir à tona. Assim, "temos fome, mas primeiramente não pensamos que o organismo queira ser conservado; esta sensação parece se impor sem razão e finalidade, ela se isola e se considera arbitrária." (NIETZSCHE, 2005, p. 28). A partir dessa reflexão, Nietzsche conclui que a fé na liberdade da vontade é um erro tão original quanto a crença em substâncias incondicionadas que remontam a um passado remoto. Original, nesse caso, justamente por ser um erro que remete às origens do intento de pensar sobre as coisas e fenômenos. Trata-se de um erro original da própria vontade de poder, como talvez Nietzsche preferisse sustentar. Essa vontade não é, pois, completamente livre.

Logo, há certa conjuntura de ordem natural subjacente a nossos juízos, nossas vontades e nossas ciências das coisas. A vontade de liberdade não é tão somente fruto de uma liberdade intrínseca que origina uma série de arbitrariedades a fim de garantir o ensejo para levar o desejo de liberdade a cabo, mas advém de um contexto natural que abastece o animal-humano dessa vontade de liberdade, tonando-a viável e pertinente ao contexto da espécie ou mesmo da cultura, do ambiente, etc. A vontade de liberdade é, portanto, vontade animal e potencialmente expansiva para uma moral integradora de novas alteridades, desde que sensível à animalidade. 


\section{Condições de Moralidade}

Não há moral completamente desatrelada das condições naturais preestabelecidas. Do mesmo modo que as diferentes culturas são tão diversas quanto variados são os ecossistemas em que se aculturaram e se desenvolvem, a questão da moralidade também variará de acordo com o ambiente físico no qual se desenvolve. $\mathrm{O}$ ambiente natural condiciona, em alguma medida, o modo de seus nativos criarem semânticas e símbolos que atribuam sentido a seu meio, seja de modo pragmático, seja de modo religioso. Consequentemente, o meio será provedor de condições e limites de valorações. Isso fica patente se se toma o exemplo de certo alimento que é cobiçado e, portanto, valorizado, pela sua escassez e dificuldade de cultivo em determinada área. Embora se trate de uma vicissitude bastante trivial de ordem prática, nota-se que a questão do valor, do bom/nobre/cobiçado em contraposição ao ordinário, está aí presente e não se pode desavi-lo por completo da conjuntura de ordem natural que o condiciona.

Cabe dizer, nesse sentido, que o imperativo categórico kantiano, logo, só poderia ter sido pensado por um sujeito que pouco contato teve com outras culturas, como foi o caso de Immanuel Kant. Não só a própria dinâmica de desenvolvimento das culturas faz divergir imensamente seus parâmetros morais quanto o próprio ambiente e grau de humanização de seus indivíduos influenciará seus costumes e o modo de lidar com a normatização dos hábitos.

Nietzsche considerará a moral kantiana como algo de uma beleza ingênua e a comparará à ideologia do livre-comércio ao destacar que sua premissa supõe "que a harmonia universal tem que produzir-se por si mesma, conforme leis inatas de aperfeiçoamento." (2005, p. 33). Ao contrário, Nietzsche apostará que uma "visão geral das necessidades da humanidade" venha a mostrar que não é desejável que os sujeitos ajam de modo homogêneo.

Sem renegar a inestimável contribuição de Kant, quero, entretanto, repensar o imperativo categórico a partir dessa perspectiva da condição de animalidade inerente ao humano. Penso ser, a animalidade, um pressuposto básico para um consenso mínimo que, diferente de uma categoria universalizante, é assimilável somente enquanto reconhecimento da alteridade. Destarte, parece-me que a animalidade constitui a unidade mínima do humano intercultural e intersubjetivamente falando. Assim, educar para o reconhecimento da animalidade é educar para uma moral fidedigna ao que é propriamente humano em todo humano e, a partir disso, potencializar vias de sensibilidade e subjetivação humanas pelo conhecimento de si enquanto sujeitos em constante devir. Isso se dá, justamente, pela abertura à animalidade produtora de vias sensíveis, por meio da própria retomada da primazia dos sentidos e, como exporei no próximo capítulo, para tanto convém reconsiderar o animal que é o outro inerente ao eu (humano) e abrir-se, assim, à alteridade absoluta que contém infinitas alternativas subjetivantes e conjunturas de subjetivação. Essa perspectiva ajuda a fugir das identidades estanques que tendem a agir para solidificar a ordem dominante e ofuscar a diferenciação criativa. 
Há, desse modo, uma raiz instintiva que nos une enquanto animais planetários e que nos move à luta pela sobrevivência, cuja importância não deve se prescindir. É nos instintos, na propensão às paixões e na capacidade sensível que encontramos nossas origens comuns.

A lei e a moral almejantes de liberdade e segurança promoveram exclusão porque principiaram por esquecer da animalidade e, sobretudo, do caráter sensível do animal-humano. $\mathrm{O}$ medo da contaminação-criativa do animal inerente fez com que o humano privasse em detrimento de educar. "O homem moral", adverte Nietzsche (2005, p. 17), "pressupõe que aquilo que está essencialmente em seu coração deve ser também a essência e coração das coisas.". Ora, a lei não advém de Deus, nem a própria moral é inerente à essência do ser. Ela é construída em sua historicidade e na historicidade das necessidades forjadas pelo humano que se sofistica e almeja transcender seu Estado natural. A correta explicação da gênese da moral, para Nietzsche, não poderá recorrer "à hipótese de intervençôes metafísicas" (2005, p. 20), mas denotar a ciência de que transita no domínio das representações. A lei, ou norma moral, não deve ter como fim a segregação entre humanos e não-humanos, entre humanos bem e mal-socializados, mas, ao contrário, faz sentido que se estabeleça na composição do eu por meio do encontro com o outro-eu. A animalidade é uma via de facilitação desse encontro por ser univocamente humana e não prescindir dos sentidos, por requerer o mergulho na alteridade pelo universo do sensível desde sua experienciação mais rudimentar: o olhar, o toque, o olfato, etc.

A propósito, lei e liberdade só existem porque existe o outro-eu a me indagar sobre o que sou. A enteléquia da lei é a composição e não a segregação. $\mathrm{O}$ ambiental e o animal não escapam a essa composição, são, ao invés, o a priori das relações e das próprias normas que são erigidas para as tornarem possíveis.

\section{Unidade Animal e Subjetivação: a questão do outro para além do outro-humano}

Ao discutir a questão do outro, a filósofa Nadja Hermann (2011) esclarece que a relação binomial entre corpo e alma estabelecida nos primórdios da Filosofia, por Platão, se associa à acepção de identidade e alteridade.

Desse modo, a identidade se constitui no âmago da alma e se relaciona à transparência. O corpo, por seu turno, como meio de se ter acesso e de se dar vazão à multiplicidade é o outro. Ele representa a porta aberta à estranheza, ao descentramento do ser igual a si mesmo e, por denotar, assim, uma séria ameaça à mesmidade, deve ser paulatinamente excluído do expediente do agir. Desse modo, ele não pode desvirtuar a alma de sua tarefa de arrazoar o ser-mesmo, legitimando o ser enquanto verdade de si, uma unidade identificável sem afecções de paixões. Disso se conclui que o que atribui identidade e humanidade ao sujeito é a alma, enquanto que o corpo representa os impulsos e instintos que devem ser controlados para se alçar à humanidade, ou seja, a animalidade, o corpo instintivo, é o outro (animal) que continuamente ameaça o espírito, o eu (humano). "A alma mantém a identidade consigo mesma, pela sua ação racional", explana Hermann, "ao passo que o corpo, provocado pela multiplicidade sensível, impulsiona-se para o distanciamento da unidade." (2011, p. 139). 
René Descartes, cerca de dois milênios depois de Platão, consolidou essa separação no âmbito cognitivo e epistemológico ao promover a dicotomização entre res cogitans e res extensa, mente e corpo, em certa medida, oblitera nossa capacidade de perceber o(s) outro(s) enquanto elemento(s) constituinte(s) do eu e mesmo como a alteridade possível do si mesmo, a pluralidade na unidade. A desagregação do sujeito, promovida por Descartes, desse modo, também materializa nossa relação com a natureza. Se é a res cogitans que me dá acesso à existência ("Penso, logo existo.") e à natureza falta essa faculdade pensante, ela pode apenas estar, mas jamais existir como sujeito, logo, ela é objeto. Não existindo, ela pode apenas ser-para-alguém não tendo, assim, fim em si mesma, tornando-se, nessa perspectiva, apenas o meio. Ao delegar o estatuto de utilidade à alteridade natural, a própria animalidade humana se torna tão somente instinto a ser controlado. $\mathrm{O}$ animal-em-mim, assim como o corpo, é a coisa-útil, e ela não pode estar no eu que existe, a coisa-útil também não é o outro-eu, é o não-eu (a negação absoluta), é o que devo controlar em mim para ser-eu, para existir.

A animalidade enquanto coisa-útil, entretanto, nessa perspectiva utilitária e segregacionista, é potência-útil do eu-pensante e sensiente. Ela me avisa, por exemplo, sobre o calor ou o frio sem resolver racionalmente o problema desses excessos. Nesse sentido, ela é o outro que serve ao eu. Serve ao eu enquanto acessibilidade ao mundo físico que é arcabouço do universo cognoscitivo e sensível. Ela é o próprio requisito à acedência à alma, à mente, ao cognoscível, ao sentimento. Não obstante, essa animalidade-alterificada concomitantemente física e instintiva só se torna uma via de acesso reconhecida pelo (auto)controle. Ao mesmo tempo em que traz consigo o caráter de via de apreensibilidade da realidade, seja em si, seja no fenômeno que integra, a animalidade-alterificada só é no embate com a inacessibilidade da sua existência per se. Isso, é claro, segundo a lógica que cinde sujeito e objeto ou, como diz Bruno Latour (2001), que se respalda na premissa de um cérebro extirpado. Nesse sentido, ele esclarece,

Quando dizemos que não existe um mundo exterior, não negamos sua existência; ao contrário, recusamo-nos a conceder-lhe a existência a-histórica, isolada, inumana, fria e objetiva que lhe foi atribuída apenas para combater a multidão. (LATOUR, 2001, p. 28)

Em resposta a pergunta que o deixou perplexo: "Você acredita na realidade?”; Latour (2001) sugere que a crença nos pressupostos do realismo e na existência de uma res extensa completamente independente da res cogitans, se sustenta, não só no temor de uma perda de conexão com a realidade (o que seria literalmente a extirpação do cérebro), mas num medo crônico por parte dos intelectuais e cientistas de um governo das massas. Isto é, o colapso da Ciência como instituição legitimadora de verdades pode significar a entrega da realidade aos menos humanizados. A "verdade" (acessível pela alma) deve estar sempre acima da intuição, da sensibilidade (acessível pelo corpo). Não havendo realidade, o estatuto de verdade se torna frívolo e tudo poderia recair sobre uma animalidade incontida, uma entrega ao fluir desarrazoado da vida. Não por acaso (e não tão somente pelo motivo aqui exposto), nota-se que a Educação prima pelas ciências em seu currículo em detrimento das artes.

Em última análise, trata-se do medo do outro vir à existência se libertando do controle, do terror da possibilidade de insurgência do corpo frente à mente, de 
que o outro adquira mais poder que o eu. Trata-se da temeridade de um governo da animalidade-coisa (que traz consigo o aflorar dos sentidos e instintos), deixando de ser apenas meio controlado para ganhar legitimidade enquanto modo de agir e existir, enquanto algo reconhecido moralmente, enquanto costume ou modo de vida, enquanto via de acesso à "verdade". Ora, no âmbito da própria ciência, a sensibilidade tem sido reconhecida como imprescindível nas pesquisas (bem como o acesso à "verdade" vem sendo considerado mais uma invenção ou uma produção do que uma descoberta) e, por vezes, objetos têm ganhado estatuto de sujeitos. Ao mesmo tempo há esforços para que isso fique restrito aos bastidores, pois o Sensível (tudo aquilo que foge do rol das coisas mensuráveis, controláveis, verificáveis) faz vir à tona o temor da animalidade e da imprevisibilidade que ela encerra.

Não obstante, como foi dito, a animalidade é uma condição a priori do humano e constitui o próprio outro-eu do sujeito em formação, senão o eu-Outro mesmo - o outro formativo do eu -, não como negatividade, mas como positividade constituinte e via para se aceder a negatividades que, pela experiência de estranhamentos, tornam-se pilares da auto(re)criação. Como atesta Félix Guattari (1992, p. 120): "A carne da sensação e matéria do sublime estão inextricavelmente misturadas". Nessa óptica, é-se humano e animal e vive-se a animalidade como abertura sensível à estranheza, enquanto via de acesso a outros-possíveis que não é mais só o acesso, mas, antes de tudo, constitui uma animalidade per se que se articula no constructo do animal-humano. É-se antes de tudo animal e, no fim das contas, apenas animal no que tange à posição intrinsecamente ecossistêmica.

Nietzsche assenta a gênese do instinto social, por assim dizer, no prazer animal que, no humano, provoca a fantasia da empatia. Nas suas palavras,

De suas relações com os outros homens o homem adquire um novo tipo de prazer, além das sensações prazerosas que retira de si mesmo; e com isso aumenta significativamente o âmbito das sensações de prazer. Nisso ele talvez tenha herdado muita coisa dos animais, que visivelmente sentem prazer ao brincar uns com os outros, sobretudo uma mãe com seus filhotes. (NIETZSCHE, 2005, p. 69)

A partir dessa colocação, ele conclui:

As manifestaçôes de prazer semelhantes despertam a fantasia da empatia, o sentimento de ser igual: o mesmo fazem os sofrimentos comuns, as mesmas tormentas, os mesmos perigos e inimigos. Com base nisso se constrói depois a mais antiga aliança: cujo sentido é defender-se e eliminar conjuntamente um desprazer ameaçador, em proveito de cada indivíduo. $\mathrm{E}$ assim o instinto social nasce do prazer. (NIETZSCHE, 2005, p. 70)

Nesse sentido, pode-se pensar que a própria tendência a se querer eliminar o "desprazer" - e, cabe dizer, a edificação da moralidade é por ela instigada - tem sua gênese numa pulsão animal, uma vez que esse "desprazer" (enquanto incômodo ou ameaça) não é primazia somente do humano. $\mathrm{O}$ instinto de acoplamento adaptativo que visa a eliminar o "desprazer" é próprio do animal e, porque não dizer, dos seres 
vivos de maneira geral. Eles, de algum modo, sempre buscam estar cômodos e seguros em seus ambientes. Por isso mesmo, a questão da moralidade e, de igual modo, a do valor e desvalor de algo, se constitui a partir de alicerces naturais. Essa premissa é - e muito provavelmente continuará a ser - fortemente negada por muitos, mas não se pode desconsiderar o fato da moral surgir como reflexão acerca da ação virtuosa, ou seja, ela nasce da reflexão sobre o que viria a ser a boa prática. Do ponto de vista pragmático, a moral inevitavelmente envolve a corporalidade, o consumo da Physis, a vida, o instinto e, portanto, engloba a instância da naturalidade, da animalidade e das relações ecossistêmicas.

Acredito, pois, que se vive num tempo em que os próprios progressos em termos de formação humana requerem a consideração da animalidade, tanto enquanto consciência ecossistêmica quanto em termos de acessibilidade ao sensível e a novas alternativas de subjetivação. Assim, nas palavras de Félix Guattari,

Produzir uma nova música, um novo tipo de amor, uma relação inédita com o social, com a animalidade: é gerar uma nova composição ontológica correlativa a uma nova tomada de conhecimento sem mediação, através de uma aglomeração pática de subjetividade, ela mesma mutante. (GUATTARI, 1992, p. 89)

A animalidade é produtiva, portanto, de outras maneiras de conhecer sobre si e sobre o outro. Dar vazão à animalidade, nesse viés, é buscar uma abertura às anomalias fora da norma comum (do conhecimento mediado), que se abrem a possibilidade de ser e devir fora do padrão capitalístico dominante de subjetivação. Mais do que isso, é ainda fomentar a potência sensitiva do animal-humano, causando a ruptura com a docilidade e domesticidade que produz formas de subjetivação homogeneizantes. Em tempos de docilização dos corpos, das mentes e dos modos, animalizar-se é produzir-se na dobra humano-animal da espécie, ensejando as anomalias que se originam

[...] na variação das séries que propagam o animal-molar, padronizado e domesticado. O animal minoritário é aquele que quebra as cadeias de propagação. A anormalidade é um certo tipo de ruptura que altera diagramas, produzindo traços inusitados e novas singularidades. Tornar-se animal não é deseducar-se, é fazer diferença, tomar-se diferente. (ZORDAN, 2002, p. 63)

Nessa perspectiva, cabe pensar como se pode educar não desanimalizando, como humanizar sem roubar do humano suas qualidades intrínsecas que o permitem se manter em conexão física e ambiental ou, melhor dizendo, que constituem qualidades a serem amadurecidas e exercitadas para o bom uso e conhecimento do corpo e a consciência ambiental, temas esses que têm ganhado repercussão e vêm sendo alvos de estudos no campo da Educação.

Propagar um dado tipo humano como ideal imutável, nesse sentido, é sempre um equívoco em termos de humanização. A animalidade instintivo-sensitiva e a sua experienciação em dado grau deixam em aberto esse bumano ideal e, por esse motivo, contribuem para a recriação da moral e para a reeducação do humano fora de um padrão instituído do que é humano. 
O livre experienciar animal dos sentidos dá vazão a um contexto de (re) criação que, experienciado por um sujeito humano, ao mesmo tempo que é escape da constrição do Estado natural, só pode se dar sob a égide desse Estado. A sensibilidade animal é a abertura a um universo de possibilidades de subjetivação, quiçá recriadoras da própria moral, agregando-lhe um caráter ecosófico ${ }^{1}$ (ecologia generalizada) centrado num valor-vida, mas não redutível a ele (GUATTARI, 2003). Uma sensibilidade que propicie a expansão a uma ampla variedade de relações que, na medida em que existem (agora com estatuto de eu-Outro), descentram, derivam, subjetivam, devêm, interpelam por respeito relacional e convocam a uma responsabilidade generalizada.

Como alternativa ao traquejo dessa sensibilidade, a arte se apresenta como um vasto campo para problematizar a esfera da animalidade na Educação. As obras literárias e cinematográficas, por exemplo, recorrentemente atribuem qualidades humanas aos animais (fala, sentimentos, pensamento, etc.) ao mesmo tempo em que lhes resguardam certas qualidades animais. Parecem, com isso, poder ser o estopim para se discutir e trabalhar a animalidade, sobretudo, com os públicos infantil e infanto-juvenil.

Há muitas críticas ao campo educacional pelo fato de pecar por falta de conectividade com a práxis e com o cotidiano. Por outro lado, a negação da animalidade é uma falta que costuma ficar fora do índex de críticas que comumente se faz à Educação e ao processo de ensino-aprendizagem de modo geral. Trata-se, porém, de uma falta tão grave quanto a completa cisão entre teoria e prática, entre conceito e realidade. Urge, assim, repensar a animalidade no que diz respeito a seu potencial de criação, de conectividade e de ampliação das possibilidades de vir a ser numa perspectiva de abertura ao sensível.

\section{Referências}

DURKHEIM, É. Educação e sociologia. Rio de Janeiro: Melhoramentos, 1978, 91p.

GUATTARI, F. As três ecologias. 14. ed. Campinas: Papirus, 2003, 56p.

GUATTARI, F. Caosmose: um novo paradigma estético. 1. ed. Rio de Janeiro: Editora 34, 1992, 208p.

HERMANN, N. Breve investigação genealógica sobre o outro. Educação e Sociedade. Campinas: Unicamp, v. 32, n. 114, p. 137-149, jan./mar. 2011.

LATOUR, B. A esperança de pandora: ensaios sobre a realidade dos estudos científicos. 1. ed. Bauru: EDUSC, 2001, 372p.

MORIN, E. A cabeça bem-feita: repensar a reforma, reformar o pensamento. 12. ed. Rio de Janeiro: Bertrand Brasil, 2006, 128p.

NIETZSCHE, F. Humano, demasiado humano. 1. ed. São Paulo: Companhia das Letras, 2005, 320p.

SCHILLER, F. A Educação estética do homem: numa série de cartas. 4. ed. São Paulo: Iluminuras, 2002, 160p.

ZORDAN, P. B. M. B. G. Devir-Animal e Educação. Educação \& Realidade. Porto Alegre: Faculdade de Educação/UFRGS, v. 27, n. 2, jul./dez., p. 59-66, 2002. 


\section{Nota}

${ }^{1}$ Félix Guattari (2003) fala de três registros ecológicos: a ecologia do meio ambiente, a das relações humanas e a da subjetividade humana. Ao pensamento ecológico que contempla esses três registros, o autor dá o nome de ecosofia. Para ele "a refundação do político deverá passar pelas dimensões estéticas e analíticas que estão implicadas” (GUATTARI, 1992, p. 33) nessas três ecologias.

* Doutorando em Educação pelo Programa de Pós-graduação em Educação da Pontifícia Universidade Católica do Rio Grande do Sul, Porto Alegre, Rio Grande do Sul, Brasil.

\section{Correspondência}

Rodrigo Avila Colla - Pontifícia Universidade Católica do Rio Grande do Sul, Av. Ipiranga, 6681, CEP: 90619-900, Partenon, Porto Alegre, Rio Grande do Sul - Brasil.

E-mail: rodrigo.a.colla@gmail.com

Recebido em 22 de janeiro de 2013

Aprovado em 20 de abril de 2014 